\title{
FACTORS ASSOCIATED WITH EXCLUSIVE BREASTFEEDING AMONG PRIMIPARA: A SCOPING REVIEW
}

\author{
Hairiana Kusvitasari, Ismarwati
}

Universitas ‘Aisyiyah Yogyakarta

\begin{abstract}
Background: The breastfeeding practice of primiparous mothers in developed and developing countries is influenced by various factors. The breastfeeding factor for primiparous mothers is closely related to their initial experience of giving breast milk to success and failure in achieving exclusive breastfeeding. The purpose of this study was to explore the factors that influence primiparous mothers in giving exclusive breastfeeding.

Subjects and Methods: This scoping review uses an electronic bibliographic database method. Articles were obtained from 5 databases, namely Science Direct, PubMed, EBSCO, Wiley and ProQuest conducted systematically from 2009 to 2019. Articles used in this scoping review were described in the Prefered Reporting System of Systematic Review and MetaAnalysis (PRISMA) flowchart.

Results: Based on 8 articles from 421 articles obtained showed that internal factors come from the mother herself and external factors that come from outside the mother were related in giving exclusive breastfeeding. Internal factors include the initial response of primiparous mothers in exclusive breastfeeding, maternal psychology when giving exclusive breastfeeding, coping with primiparous mothers during the process of giving exclusive breastfeeding, commitment of primiparous mothers to exclusive breastfeeding. Maternal external factors include social support for primiparous mothers in providing exclusive breastfeeding and socio-culture to primiparous mothers in providing exclusive breastfeeding.

Conclusion: The most influential internal factor is the primiparous mother's psychological factor. The most influential external factor is socio-culture. There are still many countries that adhere to socio-culture which can hinder the process of exclusive breastfeeding.
\end{abstract}

Keywords: exclusive breastfeeding, internal factors, external factors, mother

\section{Correspondence:}

Hairiana Kusvitasari. Universitas 'Aisyiyah Yogyakarta. Jl. Ringroad Barat No.63, Mlangi Nogotirto, Gamping, Rice Field Area, Nogotirto, Kec. Gamping, Sleman Regency, Yogyakarta Special Region 55592, Indonesia. Email: hairianasari@gmail.com: Mobile: o82251977627 